


\title{
A MULHER, A CRIANÇA E SEUS DIREITOS
}

\author{
MARIA MALTA CAMPOS \\ Fundação Carlos Chagas
}

\begin{abstract}
RESUMO
O artigo examina as concepções sobre os direitos da criança pequena à educação na legislação brasileira mais recente, à luz da evolução das definições mais gerais sobre os direitos humanos, da criança e da mulher, e das demandas trazidas pelas mobilizações de vários setores da sociedade. Discute também as contradições e obstáculos que surgem na aplicação das novas definições legais à realidade brasileira.

DIREITOS DA CRIANÇAEDOADOLESCENTE-DIREITOSHUMANOS-EDUCAÇÃO-LEGISLAÇÃOBRASIL
\end{abstract}

\footnotetext{
ABSTRACT

WOMEN, CHILDRENAND THEIR RIGHTS. The article discusses the evolution of children's and women's rights in Brazil, specially the rights of small children to education. The analysis is based on the changes is the definition of human rights in different historical contexts and on the demands brought about by the social movements that had impact on recent Brazilian legislation. The article also discusses the contradictions and barriers that have to overcome in order to apply this new legislation in the reality.
} 
Norberto Bobbio disse, em uma conferência proferida em 1964, que "o problema fundamental em relação aos direitos do homem, hoje, não é tanto o de justificá-los, mas o de protegê-los. Trata-se de um problema não filosófico, mas político" (Bobbio, 1992. p.24). Creio que podemos endossar suas palavras hoje, trinta anos depois, talvez com maior ênfase do que foram ditas na década de sessenta.

Neste final de século, a preocupação com os direitos humanos, com o exercício da cidadania e com a garantia da democracia parece ganhar um novo destaque, como se a humanidade procurasse recuperar os velhos ideais da revolução francesa no momento em que o socialismo real retrocede em várias partes do mundo, as nações se estilhaçam em conflitos étnicos e religiosos e o capitalismo rompe com as regulações políticas e sociais estabelecidas no pós-guerra.

Bobbio mostra como a formulação dos direitos do homem muda conforme mudam as condições históricas, as necessidades e interesses, as relações sociais e de poder, a ciência e a tecnologia e assim por diante. Sua análise considera que os chamados direitos "naturais" não existem enquanto critérios absolutos, mas são sempre interpretados pelos homens segundo determinados contextos sociais, culturais e políticos. A Declaração Universal dos Direitos do Homem inicia-se com a frase "Todos os homens nascem livres e iguais em dignidade e direitos". No entanto, nem todos nascem livres ou iguais, como sabemos. A liberdade e a igualdade, como lembra Bobbio, são um ideal a perseguir e não um dado natural.

Sua análise sobre a evolução da formulação dos direitos demonstra como nela incidem os desafios da história, com o impacto das guerras mundiais, dos processos de libertação dos povos colonizados, das revoluções comunistas, das tensões da guerra fria etc.

Nesse desenvolvimento, ocorrem mudanças importantes nas concepções de direitos. Por exemplo, o direito à inviolabilidade da propriedade, tão importante nas declarações do século XVIII, recua diante dos direitos coletivos no final do século $X I X$ e no século $X X$. Essa mudança reflete outras mais abrangentes, como o maior predomínio dos direitos sociais, que consistem em poderes e indicam obrigações positivas de outros, sobre os direitos individuais tradicionais, que consistem em liberdades e indicam obrigações negativas, ou seja, abstenção de determinados comportamentos (Bobbio, 1992. p.21).

Evidentemente, essas mudanças ocorrem dentro de determinados contextos históricos, quando a valorização dos direitos sociais se sobrepõe a determinados direitos individuais, os quais perdem espaço em razão de um benefício comum que se deseja atingir. Uma mudança importante ocorre também a partir das duas guerras mundiais, quando se percebe que os direitos devem ser definidos em relação a toda a humanidade e não somente a uma nação em particular.

Por outro lado, as primeiras declarações se referiam ao homem genérico ou, como queria Marx, ao burguês egoísta. A aplicação de princípios muito gerais a casos particulares nem sempre é evidente por si mesma. Olympe de Gouges percebeu bem isso, dois anos 
após a Tomada da Bastilha, ao divulgar a Declaração dos Direitos da Mulher e da Cidadã, cujo Artigo I dizia: "A mulher nasce livre e tem os mesmos direitos do homem."(Bonacchi, Groppi, 1995. p.302). A especificação de sujeitos definidos tornou-se necessária à medida que grupos discriminados da sociedade lutavam pelo acesso aos direitos definidos como de todos. As mulheres lutaram pelo direito de voto durante décadas; os negros, nos Estados Unidos, mobilizaram-se no Movimento pelos Direitos Civis da década de sessenta, reivindicando a aplicação dos direitos definidos na Constituição do país também para eles.

A partir do pós-guerra, os organismos internacionais elaboram declarações que especificam os direitos de todos: para as mulheres, em 1952, portanto, I6I anos após Olympe de Gouges; para as crianças, em 1959; para as nações colonizadas, em 1961, e para as raças discriminadas, em 1963 (Bobbio, 1992. p.99).

A Declaração dos Direitos da Criança apresenta esses direitos como uma especificação dos direitos do homem, justificando-a pelo fato de características particulares da criança, como sua imaturidade física e intelectual, levarem à necessidade de proteção e cuidados especiais. Assim, reconhece que a aplicação dos direitos do homem genérico às crianças não é evidente por si mesma. Aliás, Georges Snyders (1980) analisa bem isso, quando examina a forma como a sociedade trata as crianças, assimilando-as a outros grupos em situação de subordinação ou discriminação. Segundo sua original interpretação, a sociedade se acostumou a ver as crianças como viu os escravos, os negros, os empregados domésticos, o povo e as mulheres.

No entanto, o problema não se restringe a elaborar declarações cada vez mais específicas e detalhadas. Como argumenta Bobbio, o grande problema que decorre dessas declarações de direitos é como torná-los realidade. Pode-se supor que, se no processo do reconhecimento e formulação dos direitos concorrem fatores históricos que viabilizam essa consciência coletiva em determinados momentos, quando se tenta colocá-los em prática, o contexto social, político, cultural e econômico pode contribuir, dificultar ou até impedir essa tarefa.

Chega-se, assim, ao papel dos sujeitos sociais nesse processo. Alguns autores mostram como a tradução prática de diretrizes legais e políticas depende de fatores que conformam a ação coletiva dos grupos sociais em diferentes situações. Touraine faz uma comparação entre a tradição francesa e latina e a tradição anglo-saxônica na definição dos direitos e na construção de sistemas políticos e legais que os promovam e garantam. Segundo ele, a concepção francesa se apóia fortemente no papel do Estado como árbitro e garantia dos direitos de cidadania. Ao contrário, na tradição inglesa, é a sociedade civil a principal guardiã dos direitos individuais. Touraine mostra que o modelo republicano francês se mostrou menos compatível com a democracia do que o sistema inglês (Touraine, 1996). O conjunto de investigações relatado por Robert Putnam (1993), que monitorou, durante mais de vinte anos, o processo de descentralização governamental realizado na Itália a partir dos anos setenta, mostra como o mesmo quadro institucional produz resultados bastante diferentes nas diversas regiões da Itália. Segundo sua interpretação, desenvolvida a partir da história da 
formação social, política e econômica de cada região, a raiz das diferenças encontradas entre o sul e o norte remonta ao surgimento do que ele chama de civismo, a partir do século XII, nas cidades do norte da Itália. Contrapondo a estrutura horizontal de poder e de padrões de relacionamento do norte com a estrutura vertical e os padrões de relacionamento hierarquizados encontrados no sul, ele mostra como as mesmas regras e critérios de gestão governamental são interpretados e concretizados de forma completamente diferente nas diversas regiões.

Talvez seja possível realizar uma análise sobre a constituição desse campo "direitos da criança" no Brasil utilizando parâmetros semelhantes aos sugeridos por esses autores. Como se deu, no país, a construção social dessa agenda de questões que se definem como direitos da criança pequena à educação?' Até que ponto a formulação legal reflete um consenso da sociedade a respeito desses direitos? Quais os conflitos que se manifestam no momento em que se tenta colocá-los em prática? Quais os aspectos que ainda permanecem dúbios para a maioria dos atores sociais e quais demonstram maior capacidade de provocar mobilização social?

Para examinar a primeira questão no contexto brasileiro, torna-se necessário recuperar os diversos momentos históricos que cercaram a introdução de novas definições legais sobre a assistência e a educação de crianças pequenas.

Considerando apenas o século $X X$, o primeiro marco é sem dúvida a legislação trabalhista aprovada após o Movimento de 30, no âmbito das amplas mudanças políticas, econômicas e sociais ocorridas nesse período. A Consolidação das Leis do Trabalho — CLT, aprovada em 1934, no seu artigo 389, obriga os estabelecimentos em que trabalharem pelo menos trinta mulheres, com mais de dezesseis anos de idade, a dispor de local apropriado em que seja permitido às empregadas guardar, sob vigilância e assistência, os seus filhos no período de amamentação. $\bigcirc$ artigo 396 da mesma lei, introduzido em 1967, determina que, até que seu filho complete seis meses de idade, a mulher tem o direito, durante a jornada de trabalho, a dois descansos especiais de meia hora cada um, para amamentá-lo. $O$ período de seis meses pode ser prorrogado, a critério da autoridade competente, quando a saúde do filho o exigir (parágrafo único do mesmo artigo). A lei prevêa possibilidade de as empresas estabelecerem convênios com outras creches para o atendimento dos filhos de suas funcionárias (Teles et al. 1989).

Salvo engano, ainda resta por ser feito um estudo que desvende as origens dessa determinação legal e identifique as forças responsáveis por sua aprovação inicial e, posteriormente, pelos acréscimos e modificações. De todo modo, é interessante o fato de que a primeira vez em que é objeto de preocupação do legislador, a criança pequena em foco seja o filho de trabalhadoras mulheres, cuja saúde se quer protegida por essa medida. Assim, ao mesmo tempo que se procura salvaguardar o direito da criança à sobrevivência, resguarda-se, aparentemente de forma secundária, o direito da mãe trabalhadora a amamentá-la.

I. Oszlak e O’Donnell (1976) propõem uma metodologia de análise sobre as políticas públicas que as considera como respostas do Estado a uma "agenda de questões" que se constituem em determinados contextos sociais e momentos históricos. 
Como muitas outras, essa lei foi quase sempre descumprida no país. No entanto, estudo realizado em 1986 pelo Conselho Estadual da Condição Feminina de São Paulo, no final da década de setenta e início de oitenta, mostra que o ressurgimento do movimento feminista e da mobilização sindical coincidiu com significativo aumento no pequeno número de berçários e creches instalados em empresas paulistas: do total de 38 unidades localizadas pela pesquisa, quinze foram criadas entre 1926 e 1970, e 23 a partir da década de setenta, principalmente após 1975 (Teles et al. 1989. p. I I I-2). A realidade tentava, timidamente, aproximar-se da prescrição legal.

Ao contrário do que ocorreu no campo trabalhista, a legislação educacional parece ter estado sempre atrasada em relação à realidade. Os estudos sobre as origens das diversas modalidades de atendimento - creches, jardins da infância, escolas maternais, parques infantis, pré-escolas - mostram as primeiras unidades sendo instaladas no século passado e sua expansão ocorrendo em diversos momentos históricos: os parques infantis implantados por Mário de Andrade quando à frente do Departamento de Cultura do município de São Paulo nos anos trinta; o projeto de Creches Casulo da Legião Brasileira de Assistência — LBA, sendo desenvolvido nas décadas de setanta e oitenta; os diversos planos federais, estaduais e municipais de expansão da pré-escola, também vicejando a partir dos anos setenta, muitas vezes na forma de soluções de baixo custo e baixa qualidade; e, ao longo de todas as décadas, a oferta de vagas em estabelecimentos privados suprindo a demanda crescente por parte das famílias de classe média e alta.

A despeito desses antecedentes, a Lei de Diretrizes e Bases da Educação, finalmente aprovada em 1971, muito após os intensos debates públicos que opuseram privatistas e defensores do ensino público e laico no início da década de sessenta, dedica somente uma frase ambígua à educação das crianças menores de sete anos. Porém, cada vez em maior número, as famílias encaminham suas crianças entre zero e seis anos de idade a uma multiplicidade de formas de atendimento oferecidas por inúmeros programas instituídos por diferentes órgãos públicos, diretamente ou em convênio com entidades filantrópicas e comunitárias, e também a todo tipo de "escolinhas" particulares que vicejam em bairros de diferentes níveis sociais, sem quase nenhuma fiscalização pública.

A teoria da privação cultural e a proposta de educação compensatória, divulgadas no Brasil a partir dos anos setenta, contribuem para essa expansão, fornecendo argumentos aos sistemas educacionais públicos que buscavam dar respostas à crescente demanda e ao mesmo tempo necessitavam justificar esses programas como necessários para mitigar os enormes índices de fracasso escolar na educação básica.

Essa tendência, entretanto, vai encontrar uma forte resistência por parte dos intelectuais da educação, os quais, ao mesmo tempo em que criticam a teoria da privação cultural, defendem a prioridade do ensino fundamental obrigatório e não querem ver as poucas verbas a ele destinado divididas com a educação pré-escolar. 
Quando os movimentos sociais urbanos começam a ganhar visibilidade a partir do processo de distenção política na segunda metade da década de setenta, uma das reivindicações que aparece com força nos bairros populares das grandes cidades é a creche. Essa luta traz com ela a marca de todos esses antecedentes, mas com a adição de um componente novo, que introduz uma mudança fundamental no caráter dessa demanda. Agora são as mulheres, lutando pelo atendimento de necessidades básicas em seus bairros, que incluem a creche na agenda de reivindicações dos movimentos que protagonizam, entendendo-a como um desdobramento de seu direito ao trabalho e à participação política. Essa reivindicação facilita a convergência dos movimentos de base popular e dos grupos feministas mais intelectualizados, os quais trazem para a luta a crítica ao papel tradicional da mulher na família e a defesa da responsabilidade de toda a sociedade em relação à educação das novas gerações. "O filho não é só da mãe" dizem os cartazes nas manifestações (Rosemberg [org.], 1989; Campos, 1990).

O depoimento de uma militante do movimento de luta por creches de São Paulo, colhido em pesquisa realizada pela Fundação Carlos Chagas, ilustra bem esse momento:

.... movimento feminista aí ajudou muito a gente a ter visão assim do direito da mulher, sabe? Não só da mulher que precisa trabalhar fora para sobreviver, mas o direito de todas as mulheres terem lugar para colocar o filho, para poder ser independente economicamente, ter uma profissão (...) ser um movimento, né, como um direito de todas as crianças, não só a criança da classe pobre, mas como um direito da mulher e da criança. Porque eu acho que só a mulher saindo de casa (...) que ela vai ser mais ela, né? (Campos, Rosemberg, Cavasin, 1988. p.87)

A luta por creches tem desdobramentos também no movimento sindical: pela primeira vez em muitos anos, reivindicações específicas das mulheres trabalhadoras da indústria e do setor de serviços - principalmente bancárias e funcionárias públicas - são incorporadas às pautas de negociação, entre elas a creche (Rosemberg [org.], 1989).

$\bigcirc$ impacto mais direto desses movimentos não vai se dar imediatamente no setor educacional, mas principalmente nas áreas de assistência social e, em certa medida, também no campo das relações trabalhistas. Os órgãos públicos que são instados a dar respostas ao movimento social são aqueles que tradicionalmente se ocupam do atendimento em creches: as secretarias estaduais e municipais de bem-estar social e, no âmbito federal, a LBA. Nessas instituições, os profissionais que detém a competência técnica acumulada sobre esse serviço são principalmente as assistentes sociais. As diretrizes adotadas baseiam-se em conhecimentos da área de saúde e nutrição e na tradição de desenvolvimento comunitário do serviço social. A preocupação pedagógica geralmente só se manifesta em relação aos grupos de crianças com idades próximas a 7 anos. Muitas vezes, as mesmas mulheres que se manifestam nos movimentos vêm trabalhar nas creches, mão de obra barata sem formação profissional, enfrentando longas jornadas de trabalho em penosas condições. Ao contrário do que sonhava a militante acima citada, as creches vão atender a população mais empobrecida, constituindo uma rede educacional paralela e segregada. 
Assim, quando no início dos anos oitenta a transição para a democracia política permite a eleição dos primeiros governos de oposição em estados e municípios, a realidade do atendimento e as características da demanda configuram uma problemática bastante complexa que começa a ser enfrentada por equipes integradas, em muitos casos, por ex-militantes do movimento social e dos partidos políticos de esquerda.

Nessa conjuntura, um personagem, até então em segundo plano, ganha destaque: a criança. Pelos primeiros diagnósticos, realizados muitas vezes com a colaboração da universidade, emerge um quadro dramático do atendimento existente na maioria das creches: a despeito da enorme dedicação de alguns e de complicadas e custosas estruturas técnicas em muitas agências oficiais, a baixa qualidade dos serviços constitui uma real ameaça ao desenvolvimento integral das crianças atendidas.

A consciência crescente dessas deficiências vai finalmente fazer convergir as preocupações desse campo constituído pelo movimento das mulheres e o campo educacional. Os anos oitenta vão assistir ao fortalecimento de uma subárea da educação que procura integrar a pré-escola e a creche no mesmo campo temático, trazendo o desenvolvimento da criança para o primeiro plano. É interessante observar a mudança do discurso ocorrida no âmbito dos espaços ocupados pelas feministas, como o Conselho Estadual da Condição Feminina de São Paulo e o Conselho Nacional dos Direitos da Mulher, e também nos espaços educacionais, como a Associação Nacional de Pós-Graduação e Pesquisa em Educação — ANPEd e as Conferências Brasileiras de Educação - CBEs. As lutas deslocam-se das ruas e praças e ocupam os espaços mais formalizados dos Conselhos, das associações, dos sindicatos, das universidades, dos parlamentos e dos órgãos oficiais das novas administrações.

Um documento importante para entender esse momento surge a partir das articulações promovidas pelo Conselho Nacional dos Direitos da Mulher — CNDM: é a Carta de Princípios Criança: Compromisso Social. Nele, defende-se a creche "como um direito da criança e não apenas da mãe trabalhadora; como conseqüência, postula-se que a socialização da jovem geração é uma tarefa a ser assumida pela sociedade e não apenas pela mulher-mãe" (CNDM, 1986, Introdução. p.5) Dessa posição decorre a proposta para a nova Constituição de que "a creche seja entendida como uma extensão do direito universal à educação para o cidadão-criança na faixa etária de zero a seis anos”. A Carta de Princípios explicita três significados decorrentes dessa posição: o primeiro ressalta que esse é um direito conquistado e não um ato de benevolência; o segundo defende a creche como uma instituição educativa e não apenas custodial; o terceiro enfatiza que todas as crianças são portadoras desse direito e não apenas os filhos das mães trabalhadoras (CNDM, 1986. p.31-32). ${ }^{2}$

2. Dez anos antes, em pleno regime militar, um número inteiro do jornal Movimento havia sido censurado. Ele continha uma longa matéria sobre creches, a qual serviria de subsídio para o depoimento feito por uma equipe da Fundação Carlos Chagas na abertura da Comissão Parlamentar de Inquérito sobre a Discriminação da Mulher, instaurada pelo Senado Federal em 1977 (Rosemberg [org.] 1989. p.97). 
Os debates na área educacional, nesse mesmo ano, parecem refletir essas posições. O documento da ANPEd, aprovado em junho, propõe a extensão progressiva da oferta de ensino pré-escolar público a todas as crianças de quatro a seis anos. Em setembro do mesmo ano, na IV CBE, amplia-se consideravelmente a proposta, definindo que "É obrigação do Estado oferecer vagas em creches e pré-escolas para crianças de 0 a 6 anos e II meses, que terão prioritariamente caráter pedagógico" e também que as crianças de 6 anos de idade têm direito a ingressar no ensino de $1^{\circ}$ grau. (Campos, 1989. p.247).

Essas mudanças acirram disputas em alguns campos profissionais. Discute-se se as creches devem vincular-se à educação ou à assistência social: na área educacional, há uma resistência grande em acolher a creche como parte integrante da educação pré-escolar e uma rejeição às atividades de cuidado, consideradas "assistencialistas"; na área de serviço social, defende-se uma competência acumulada sobre a gestão de equipamentos comunitários e sobre o atendimento de populações marginalizadas.

Aproximando-se o momento de votar a nova Constituição do país, um outro movimento vem compor esse quadro multifacetado, trazendo os direitos das crianças e adolescentes como sua principal bandeira. Com origens nos grupos de defesa de direitos humanos, esse movimento é integrado por profissionais e militantes que atuam junto a crianças e adolescentes marginalizados, nas ruas e nas instituições para menores considerados delinqüentes. Suas atividades desdobram-se em denúncias sobre a violência contra essas crianças e jovens e em programas de atendimento àqueles que trabalham e mendigam pelas ruas das grandes cidades. Em certa medida, esses grupos compartilham dos mesmos espaços institucionais das creches, mas sua abordagem está mais centrada em situações de emergência e a maioria das crianças objeto de sua preocupação têm mais de sete anos de idade.

A Constituição de 1988 é o novo marco legal no qual desembocam todas essas lutas e demandas: as que vêm da educação, formuladas de maneira a integrar a creche e a préescola no sistema educacional; as que se originam do movimento das mulheres, contempladas nessa proposta para a educação e na ampliação do direito à creche no local de trabalho também para os filhos dos trabalhadores homens e para toda a faixa dos zero a seis anos; as trazidas pelo movimento dos direitos humanos que dão origem ao Título 8, Capítulo 7 da Constituição, "Da família, da criança, do adolescente e do idoso". ${ }^{3}$ De forma geral, a nova Constituição amplia consideravelmente essas definições legais, tornando-se um marco na história da construção social desse novo sujeito de direitos, a criança pequena.

A resposta à segunda questão colocada anteriormente, sobre os conflitos que se manifestam no momento de colocar em prática essas novas definições legais, requer a consideração de vários aspectos. $\bigcirc$ primeiro é a mudança na conjuntura política e econômica, com a introdução das reformas neoliberais que afetam as políticas sociais voltadas para as populações mais pobres, justamente no momento em que diminuem as oportunidades de empre-

3. Posteriormente, o mesmo movimento ajuda a aprovar o Estatuto da Criança e do Adolescente. 
go e de geração de renda. Em decorrência dessas reorientações, as conquistas da Constituição passam a ser vistas como entraves às reformas, sendo que diversos de seus dispositivos são modificados pelo Congresso durante os anos noventa. Nesse contexto de enxugamento dos recursos públicos disponíveis para as políticas sociais, passam a ter destaque os programas que buscam eficiência e procuram destacar segmentos da população como alvo preferencial de determinados tipos de atendimento, sendo as políticas de cunho universalista rejeitadas com argumentos que ressaltam sua inviabilidade econômica.

A legislação complementar que vai sendo promulgada após a Constituição reflete as contradições entre esses dois momentos, por um lado confirmando uma série de conquistas, mas também introduzindo dispositivos que abrem caminho para retrocessos. $\bigcirc$ texto da nova Lei de Diretrizes e Bases da Educação aprovada em 1996 já não é o mesmo exaustivamente debatido por vários setores sociais e inicialmente aprovado na Câmara de Deputados do Congresso Nacional. Assim mesmo, ele reafirma os avanços da Constituição no que diz respeito à educação das crianças de zero a seis anos, o que significa que muitas das conquistas pelas quais lutaram inicialmente os movimentos de mulheres foram incorporadas à lei educacional.

Atualmente, ao mesmo tempo em que prossegue o ajustamento legal e institucional nos três niveis governamentais, especialmente nos Conselhos de Educação, diminui o ritmo de expansão do atendimento em muitas redes de ensino estaduais e municipais, tendência que pode estar sendo acentuada pelos efeitos da aplicação da subvinculação de recursos determinada pelo Fundo de Manutenção e Desenvolvimento do Ensino Fundamental e de Valorização do Magistério - FUNDEF. ${ }^{4}$ No plano federal, as ações se concentram na elaboração de diretrizes curriculares e nas novas propostas para a formação de professores. No plano local, as redes de ensino tentam adaptar-se às mudanças legais, o que inclui a absorção das creches pelo sistema educacional. Nesse processo, apresentam-se oportunidades de melhoria de qualidade no atendimento, mas também dificuldades em uma série de aspectos.

Aqui já seria possível começar a tentar responder à terceira questão arrolada acima, a qual se refere à percepção que os diferentes atores sociais têm sobre esses direitos e sua tradução em políticas educacionais e práticas pedagógicas. A experiência vivida mostra que a disseminação de novas concepções de direitos na sociedade geralmente é mais lenta e descontínua do que fazem supor as lutas políticas responsáveis por seu reconhecimento legal. Muitas vezes, as novas concepções são absorvidas superficialmente pelo discurso, mas nem por isso integram a prática adotada por órgãos locais de supervisão e pelos profissionais que se ocupam diretamente das crianças.

Talvez uma das razões que contribuam para essa dificuldade seja o fato de que as prescrições legais, assim como as pedagógicas, apareçam para a maioria das pessoas como destituídas de história, deduzidas de princípios abstratos e não como conquistas que decor-

4. $O$ Fundo subvincula parte dos recursos vinculados a gastos com ensino ao ensino fundamental, diminuindo a margem de opção para estados e municípios financiarem os postos com educação infantil. 
rem de longas e penosas disputas na sociedade, vividas por pessoas de carne e osso. No caso da educação da criança pequena, a inclusão das creches no sistema educacional não garante, por si só, a superação de uma tradição que sempre considerou esse atendimento como "mal menor" justificável somente para as crianças da pobreza. Na área da educação, há uma recuperação desse mesmo significado, acrescido do estigma adicional carregado por qualquer tipo de atendimento que escape do modelo estritamente escolar, geralmente alcunhado de "assistencialista". A dimensão de cuidado, assim, tende a ser considerada como algo menor. Não há nada mais revelador dessa mentalidade do que os currículos geralmente adotados nas escolas de formação de professores para a educação infantil.

Por outro lado, as instituições educacionais no Brasil estão acostumadas a trabalhar com o conceito abstrato de "aluno", sem considerar a criança ou adolescente concreto que se esconde atrás desse rótulo, com sua história de vida, sua família, sua realidade. A idéia de um atendimento opcional à criança pequena, que seja aberto às necessidades das famílias e entendido como um espaço alternativo de socialização, dificilmente se encaixa nos parâmetros organizacionais dos sistemas de educação. Os profissionais dessa área geralmente têm dificuldades em se relacionar com as famílias e os grupos de fora da escola.

Mas, assim como já ocorre em outros países, as demandas sociais evoluem e o conceito de infância se modifica, inclusive nas camadas populares. Como mostra Fúlvia Rosemberg, com base em revisão da bibliografia especializada internacional, dissemina-se uma nova concepção de educação infantil compartilhada, a qual não significa necessariamente o início precoce das aprendizagens escolares, mas procura garantir para as crianças criadas em famílias menores "experiências diversas e favoráveis a seu desenvolvimento psicológico" (Rosemberg, 1994. p.4).

A recuperação da história da luta pela ampliação dos direitos à educação das crianças pequenas mostra que os movimentos de mulheres desempenharam um papel decisivo em vários momentos dessa trajetória. $\bigcirc$ reconhecimento dessa contribuição parece importante para que as propostas de políticas de educação infantil, inclusive no nível pedagógico, integrem uma concepção de educação que reconheça o direito das famílias a contarem com espaços alternativos de educação para seus filhos pequenos e o direito das crianças a serem respeitadas em suas necessidades integrais de desenvolvimento.

\section{REFERÊNCIAS BIBLIOGRÁFICAS}

BOBBIO, N. A Era dos direitos. Rio de Janeiro: Campus, 1992.

BONACCHI, G., GROPPI, A. (orgs.) O dilema da cidadania: direitos e deveres das mulheres. São Paulo: UNESP.

CAMPOS, M. M. M. A Educação da criança de 0 a 6 anos na legislação. In: ROSEMBERG, F. (org.). Creche. São Paulo: Cortez, Fundação Carlos Chagas, 1989. p. 236- 5 I. 
. A Questão da creche: história de sua construção na cidade de São Paulo. Revista Brasileira de Estudos Pedagógicos. Brasilia: INEP, v.7I, n. 169, p. 212-31, set./dez. 1990.

CAMPOS, M. M. M., ROSEMBERG, F., CAVASIN, S. A Expansão da rede de creches no município de São Paulo durante a década de 70. (Segunda parte). São Paulo: Fundação Carlos Chagas, 1988. Mimeo.

CONSELHO NACIONAL DOS DIREITOS DA MULHER. Criança: compromisso social.. Brasília: CNDM, 1986. (Relatório do Encontro Nacional sobre Políticas de Atendimento à Criança de 0 a 6 Anos.)

OSZLAK, O., O'DONNELL, G. Estado y políticas estatales en América Latina: hacia una estratégia de investigación. Buenos Aires: CEDES/G.E.CLACSO, 1976. Mimeo.

PUTNAM, R. D. Making democracy work. Civic traditions in modern Italy. New Jersey: Princeton University Press, 1993.

ROSEMBERG, F. (org.) Creche. São Paulo: Cortez; Fundação Carlos Chagas, 1989. p.90103: $\bigcirc$ Movimento de mulheres e a abertura política no Brasil: o caso da creche. . Fecundidade, educação infantil e gênero. São Paulo, 1994. (mimeo)

ROSEMBERG, F., CAMPOS, M. M., PINTO, R. P. Creches e pré-escolas. São Paulo: Nobel; Conselho Estadual da Condição Feminina, 1985. (Década da Mulher)

SNYDERS, G. // n'est pas facile d'aimer ses enfants. Paris: Presses Universitaires, 1980.

TElES, M. A. A.; MEDRADO, M. A., GRAGNANI, A. M. C. Creches e berçários em empresas privadas paulistas. IN: ROSEMBERG, F. (org.). Creche. São Paulo: Cortez; Fundação Carlos Chagas, 1989. p. 104- 34.

TOURAINE, A.. O que é a democracia? Petrópolis: Vozes, 1996. 